\title{
BMJ
}

\section{Paracetamol use in early life and asthma: prospective birth cohort study}

\author{
Adrian J Lowe, research fellow, ${ }^{1,2}$ John B Carlin, director of Clinical Epidemiology and Biostatistics Unit, 1,2 \\ Catherine M Bennett, associate professor, ${ }^{2}$ Clifford S Hosking, paediatric allergist, ${ }^{3}$ Katrina J Allen, paediatric \\ gastroenterologist/allergist, ${ }^{1}$ Colin F Robertson, respiratory physician, ${ }^{1}$ Christine Axelrad, research nurse, ${ }^{1}$ \\ Michael J Abramson, deputy head of department, ${ }^{4}$ David J Hill, senior consultant allergist, ${ }^{1}$ Shyamali C \\ Dharmage, principal research fellow ${ }^{1,2}$
}

\begin{abstract}
${ }^{1}$ Murdoch Childrens Research Institute, Royal Children's Hospital, Parkville, Vic 3052, Australia

${ }^{2}$ Centre for Molecular,

Environmental, Genetic and Analytic Epidemiology, School of Population Health, University of Melbourne, Carlton, Vic 3053, Australia

${ }^{3}$ Department of Paediatrics, John
\end{abstract} Hunter Children's Hospital, New Lambton, Newcastle, NSW 2305, Australia

${ }^{4}$ Department of Epidemiology and Preventive Medicine, Monash University, The Alfred Hospital, Melbourne, Vic 3004, Australia Correspondence to: A Lowe lowe.adrian@gmail.com

Cite this as: BMJ 2010;341:c4616 doi:10.1136/bmi.c4616

\section{ABSTRACT}

Objective To determine if use of paracetamol in early life is an independent risk factor for childhood asthma.

Design Prospective birth cohort study.

Setting Melbourne Atopy Cohort Study.

Participants 620 children with a family history of allergic disease, with paracetamol use prospectively documented on 18 occasions from birth to 2 years of age, followed until age 7 years.

Main outcome measures The primary outcome was childhood asthma, ascertained by questionnaire at 6 and 7 years. Secondary outcomes were infantile wheeze, allergic rhinitis, eczema, and skin prick test positivity. Results Paracetamol had been used in 51\% (295/575) of children by 12 weeks of age and in $97 \%(556 / 575)$ by 2 years. Between 6 and 7 years, 80\% (495/620) were followed up; $30 \%$ (148) had current asthma. Increasing frequency of paracetamol use was weakly associated with increased risk of childhood asthma (crude odds ratio $1.18,95 \%$ confidence interval 1.00 to 1.39 , per doubling of days of use). However, after adjustment for frequency of respiratory infections, this association essentially disappeared (odds ratio 1.08, 0.91 to 1.29). Paracetamol use for non-respiratory causes was not associated with asthma (crude odds ratio $0.95,0.81$ to 1.12 ).

Conclusions In children with a family history of allergic diseases, no association was found between early paracetamol use and risk of subsequent allergic disease after adjustment for respiratory infections or when paracetamol use was restricted to non-respiratory tract infections. These findings suggest that early paracetamol use does not increase the risk of asthma.

\section{INTRODUCTION}

Paracetamol (acetaminophen) is the most commonly used analgesic in young children. ${ }^{1}$ Some evidence suggests that ingestion of paracetamol in early life may cause asthma, eczema, and allergic rhinitis in some children. $^{2-7}$ Exposure to paracetamol may increase respiratory oxidative stress by depleting glutathione in the lungs, ${ }^{8}$ thereby enhancing airway inflammation and bronchoconstriction. ${ }^{2}$ Decreased glutathione concentrations may also induce a shift from a T helper cell type 1 response to a T helper cell type 2 response with cytokine production favouring the development of allergic disease. ${ }^{9}$ Given the current global burden of asthma, ${ }^{10}$ if paracetamol is a cause of asthma its use needs to be urgently re-evaluated, particularly in the first two years of life during pulmonary development. ${ }^{11}$

The largest study to consider this question was the International Study of Asthma and Allergy in Childhood (ISAAC) phase III, which included data from 72 countries. It showed that exposure to paracetamol in the first year of life was associated with an increased risk of asthma at age 6-7 years (odds ratio adjusted for sex, region of the world, language, and gross national income: $1.46,95 \%$ confidence interval 1.36 to 1.56 ), allergic rhinitis $(1.48,1.38$ to 1.60$)$, and eczema (1.35, 1.26 to 1.45$){ }^{7}$ However, the results from ISAAC may have been confounded by respiratory infections in early life. Respiratory infections are commonly treated with paracetamol, ${ }^{1}$ and a history of respiratory infections, particularly lower respiratory tract infections, is a known risk factor for asthma. ${ }^{12-16}$ In addition, the ISAAC findings may have been affected by recall bias ${ }^{17}$; both the outcome of asthma and paracetamol exposure in the first year of life were measured when the child was 7 years old. Parents of children with asthma are possibly more likely to report use of paracetamol in early life. ${ }^{18}$ Moreover, the researchers did not assess the dose-response relation between exposure to paracetamol and risk of allergic disease, which would help to substantiate a causal argument. ${ }^{19}$

In a birth cohort of infants at high risk of developing atopic conditions, we analysed whether use of paracetamol in infancy influenced the subsequent development of asthma and allergic diseases according to indication for use.

\section{METHODS}

\section{Study population}

The Melbourne Atopy Cohort Study recruited 620 infants before birth, between 1990 and 1994 in 
Melbourne, Australia. Infants were eligible to be enrolled if one or more of their first degree family members had eczema, asthma, allergic rhinitis, or severe food allergy. The recruitment process has been described in more detail elsewhere. ${ }^{20}$ All mothers gave informed consent.

\section{Data collection}

After the birth of the infant, an allergy trained nurse (CA) did a telephone survey every four weeks until the age of 64 weeks and then at 78 weeks and at 2 years (a total of 18 times). Each survey documented any illnesses since the previous interview and oral exposures to food or medicine, including paracetamol. The number of episodes, the days of use, and the reason for the administration of paracetamol were recorded for each exposure. An annual telephone interview took place from 3 to 7 years of age

One of three allergy trained research nurses did skin prick tests at 6,12 , and 24 months, using a standard technique. ${ }^{21}$. Allergen extracts used were cows' milk, egg white, peanut, house dust mite, rye grass, and cat dander (Bayer, Spokane, WA, USA), and tests were read at 15-20 minutes.

\section{Definitions}

\section{Total days of paracetamol use}

We recorded the number of days of exposure to paracetamol for each child (regardless of dose or frequency per day) within the first two years of life. This included exposure to any preparation that contained paracetamol. Each child potentially had from zero to a maximum of $730(2 \times 365)$ "total days" of paracetamol use in the first two years of life.

\section{Indication for paracetamol use}

We classified the reason for use of paracetamol for each episode of illness for each child into one of four categories (table 1). We partitioned the total days of paracetamol use into these categories and assigned each child a value for days of exposure for each category (zero if never given for any illness in that category). We also collected parental report of contact with medical professionals for four different kinds of infection (otitis media, upper respiratory tract infection,

\section{Table 1 |Classification of indications for exposure to paracetamol}

\begin{tabular}{lll} 
Category & $\begin{array}{l}\text { Description of indications } \\
\text { symptoms }\end{array}$ & $\begin{array}{l}\text { Episodes of paracetamol exposure due to lower respiratory tract } \\
\text { infection, asthma, wheeze of any cause, bronchitis, bronchiolitis, or } \\
\text { croup, regardless of any other concomitant reasons for administration }\end{array}$ \\
\hline $2 \quad$ Eczema/allergy & $\begin{array}{l}\text { Episodes of paracetamol exposure due to eczema or food reaction, } \\
\text { regardless of any other concomitant reasons in category 3 or 4. Although } \\
\text { paracetamol is not recommended for these conditions, some parents } \\
\text { reported using paracetamol for these conditions }\end{array}$ \\
\hline $3 \quad$ Symptoms & $\begin{array}{l}\text { Episodes of paracetamol exposure due to upper respiratory tract } \\
\text { infection, otitis media, tonsillitis, or throat infection, regardless of any } \\
\text { other concomitant reasons in category } 4\end{array}$ \\
\hline 4 & $\begin{array}{l}\text { Episodes of paracetamol exposure due to gastroenteritis, conjunctivitis, } \\
\text { fever without associated evidence of respiratory tract infection, } \\
\text { immunisations, or physical injury. This was the form of exposure of } \\
\text { primary interest }\end{array}$ \\
\hline
\end{tabular}

bronchitis, and gastroenteritis) 18 times in the first two years of life, regardless of treatment with paracetamol.

\section{Childhood outcomes}

We based the following definitions for childhood outcomes on parental report from telephone interviews when children were aged 6 or 7 years. We defined current childhood asthma as one or more episodes of asthma diagnosed by the family physician in the previous 12 months. This was the primary outcome. We defined current childhood eczema as one or more episodes of eczema diagnosed by the family physician in the previous 12 months. We defined current childhood allergic rhinitis as one or more episodes of nasal discharge or congestion, in the absence of an upper respiratory tract infection, in the previous 12 months, which either the family physician or parent attributed to allergic rhinitis (hay fever) and which was treated with an antihistamine, a nasal steroid, or both. ${ }^{22}$

We used the following definitions for outcomes within the first two years of life. Infantile eczema was a parental report of either a doctor's diagnosis of eczema or any rash that was treated with a topical steroid preparation (excluding rash that affected only the scalp or nappy region). ${ }^{23}$ Infantile wheeze was a parental report of a doctor's diagnosis of an asthma-like condition before 2 years of age. We defined a positive skin prick test as a weal of at least $3 \mathrm{~mm}$ (mean) in diameter to any allergen with a positive (histamine) control.

\section{Statistical analysis}

We compared total days of paracetamol use in the first two years of life, for any cause and for each category, between children who developed asthma and those who did not develop asthma. Because of skewed distributions, we report medians and interquartile ranges along with Mann-Whitney tests.

Next, we used logistic regression models to estimate associations between total paracetamol use (regardless of indication for use) and risk of each allergic disease outcome. We used total episodes of exposure and total days of paracetamol use as potential continuous predictors. We applied a log (base 2) transformation (with an offset of 1 added) for days of paracetamol exposure, allowing interpretation of the corresponding odds ratios as the effect of doubling the days of use of paracetamol. For the outcomes at 6 and 7 years of age, we used generalised estimating equations to enable a single combined analysis with outcome data from 6 and 7 years, with allowance for repeated measures. ${ }^{15}$

We made adjustments for known potential confounders: infant's sex, parental history of asthma or eczema, and presence of older siblings at the time of birth, all determined at recruitment during pregnancy. The final model adjusted for the frequency of medical contact for infections (otitis media, upper respiratory tract infection, bronchitis, and gastroenteritis).

To determine if the indication for use of paracetamol affected the association with each of the outcomes, we restricted the above analysis to each specific indication for which paracetamol was used. We used days of use 
Table 2 | Paracetamol intake up to 2 years of age according to stated reason for use $(n=575)$

\begin{tabular}{|c|c|c|c|c|c|}
\hline \multirow[b]{2}{*}{ Reason for use } & \multirow{2}{*}{$\begin{array}{l}\text { No (\%) children } \\
\text { exposed }\end{array}$} & \multicolumn{2}{|c|}{ Episodes of exposure* } & \multicolumn{2}{|c|}{ Cumulative days of exposure* } \\
\hline & & Median (IQR) & Range & Median (IQR) & Range \\
\hline Any indication & $556(96.7)$ & $7(4-9)$ & $1-16$ & $17(10-27)$ & $1-84$ \\
\hline Lower respiratory tract symptoms & 104 (18.1) & $1(1-1)$ & $1-5$ & $4(2-5)$ & $1-27$ \\
\hline Allergy & $13(2.3)$ & $1(1-1)$ & $1-2$ & $2(2-3)$ & $1-8$ \\
\hline Upper respiratory tract symptoms & $510(88.7)$ & $3(2-5)$ & $1-12$ & $9(5-16)$ & $1-69$ \\
\hline Non-respiratory illness & $537(93.4)$ & $3(2-5)$ & $1-11$ & $7(4-11)$ & $1-50$ \\
\hline
\end{tabular}

$\mathrm{IQR}=$ interquartile range.

*Calculated in children exposed to paracetamol for each reason.

for each category (table $1, \log$ transformed) as continuous predictors in logistic regression models. We made adjustments for confounders as described above.

\section{RESULTS}

Study population and paracetamol exposure

Of the 620 infants in the Melbourne Atopy Cohort Study, $575(92.7 \%)$ were followed to age 2 years $(25$ were lost to follow-up, 14 refused participation, and six were missed at 2 years but rejoined the study after this time). A total of 495 (79.8\%) completed a follow-up at either 6 or 7 years or both (88 lost, 37 refused participation). Children who were lost to follow-up were not systematically different in terms of exposure to paracetamol or early signs of allergic disease (infantile wheeze, eczema, and skin prick test reactivity) (data available on request). Details of the demographics of the Melbourne Atopy Cohort have been previously reported. ${ }^{20}$

Almost all $(97 \%, 556 / 575)$ infants received paracetamol during the first two years of life (table 2). The median age at first exposure was 12 (interquartile range 12-20) weeks (fig 1). Of the children exposed to paracetamol within the first two years, the median total number of days of exposure was 17 (10-27). Most children (537) were exposed to paracetamol for nonrespiratory illnesses (table 2), and the next most common indication was upper respiratory tract infections. Weak correlations existed between the days of use for each of the indications (highest Spearman's $\rho=0.22$ ).

Total episodes of exposure and cumulative days of exposure were highly correlated (Spearman $\rho$ ranged from 0.81 to 0.89$)$. As the findings with respect to associations between the two measures of paracetamol exposure and the outcomes were similar, we report only the associations with cumulative days of exposure.

\section{Frequency of outcomes}

The cumulative incidence of eczema up to 2 years of age was 45.9\% (264/575). At age 6-7, 29.9\% (148/495) of children had current childhood asthma, 23.6\% $(117 / 495)$ had current allergic rhinitis, and $31.8 \%$ (157/493) had current childhood eczema. Skin prick tests were done on 445 children at 2 years of age, and $30.3 \%(135 / 445)$ reacted to one or more allergens.

Total days of paracetamol use

The total number of days of paracetamol use in the first two years of life was slightly higher in children who had current childhood asthma or allergic rhinitis (fig 2, table 3). The unadjusted regression analysis showed that a greater number of days of paracetamol exposure (all causes) was associated with increasing risk of childhood asthma (odds ratio 1.18, 95\% confidence interval 1.00 to 1.39 per doubling of days of paracetamol use) (table 4). We also found an association for the outcomes of allergic rhinitis and infantile wheeze but no clear evidence of associations with eczema or skin prick test positivity at 2 years of age (table 4 ). Adjustment for standard confounders (table 4, model 2) did not alter the observed associations. However, adjustment for frequency of medical contact for infections, particularly frequency of respiratory tract infections, attenuated the strength of the association with childhood asthma (table 4, model 3), leaving no evidence of an independent association.

Paracetamol use for non-respiratory illness

We found no evidence of any association between paracetamol use for non-respiratory illness (category 4 ) and risk of any allergic disease outcome (tables 3 and 5 , fig 2).

\section{Paracetamol use for lower respiratory tract illness}

Use of paracetamol for lower respiratory tract symptoms (category 1) was strongly associated with increased risk of childhood asthma (odds ratio 1.49, 1.25 to 1.78 , per doubling of days) (table 3, fig 2). Two hundred and forty-four children had lower respiratory tract symptoms (infantile wheeze, bronchitis, or drugs for lower respiratory tract symptoms). In this subgroup, 43\% (104/244) had received at least one

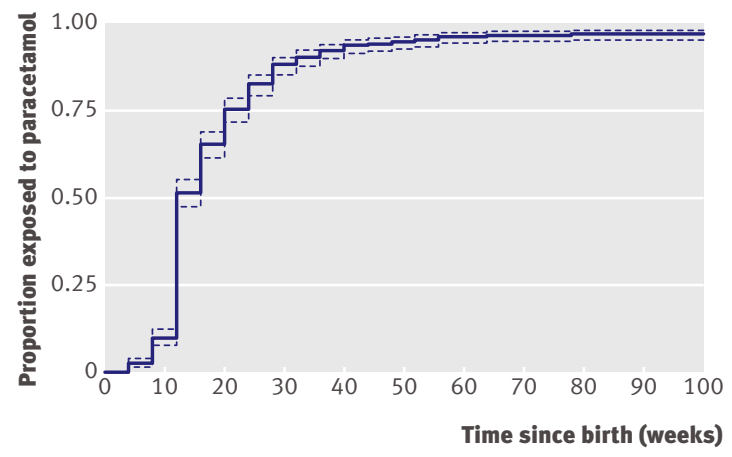

Fig 1| Age at first introduction of paracetamol (with 95\% confidence interval) 
Table 3|Paracetamol use in early life among children with and without childhood asthma and allergic rhinitis. Values are medians (interquartile range) unless stated otherwise

\begin{tabular}{|c|c|c|c|c|c|c|}
\hline \multirow[b]{2}{*}{ Reason for use } & \multicolumn{3}{|c|}{ Asthma at age 6-7 years } & \multicolumn{3}{|c|}{ Allergic rhinitis at age 6-7 years } \\
\hline & No $(n=347)$ & Yes $(n=148)$ & $P$ value* & No $(n=378)$ & Yes $(n=117)$ & $P$ value* \\
\hline Any indication & $16(9-25)$ & $18(10.5-29)$ & 0.05 & $16(9-26)$ & $19(12-31)$ & 0.01 \\
\hline Lower respiratory tract symptoms & $0(0-0)$ & $0(0-2)$ & $<0.01$ & $0(0-0)$ & $0(0-3)$ & $<0.01$ \\
\hline Upper respiratory tract symptoms & $7(3-14)$ & $9(4-17)$ & 0.04 & $8(3-14)$ & $10(5-17)$ & 0.01 \\
\hline Non-respiratory illness & $6(3-10)$ & $6(3-10)$ & 0.53 & $6(3-10)$ & $6(3-9)$ & 0.48 \\
\hline
\end{tabular}

*Mann-Whitney $\mathrm{U}$ tests.

day of paracetamol for lower respiratory tract symptoms. When we restricted the analysis to the subgroup who had lower respiratory tract symptoms, we found minimal evidence that any use (odds ratio $1.16,0.68$ to $1.98)$ or frequent use $(1.12,0.91$ to 1.38 per doubling of days) of paracetamol for lower respiratory tract symptoms was associated with increased risk of childhood asthma.

\section{Paracetamol use for upper respiratory tract illness}

Paracetamol use for upper respiratory tract symptoms (category 3) was associated with increased risk of childhood asthma (odds ratio $1.20,1.05$ to 1.38 , per doubling of days) (table 3). Only $2.4 \%$ of children (14/ 575) did not have upper respiratory tract symptoms within the first two years of life. The number of events of upper respiratory tract symptoms was strongly related to increased risk of childhood asthma $(35 \%$, $14 \%$ to $61 \%$, per event). When we adjusted the days of paracetamol use for upper respiratory tract symptoms for the number of events, the evidence of an association was substantially attenuated $(1.10,0.95$ to 1.28$)$.

\section{DISCUSSION}

Consistent with previous studies in this area, ${ }^{72425}$ this prospective cohort study found evidence of a crude association between paracetamol use in early life and increased risk of asthma. However, we found no evidence of such an association after adjustment for history of early infections, nor when the association was limited to paracetamol use for non-respiratory tract illness. Moreover, although use of paracetamol for lower respiratory tract infections and wheeze was associated with increased risk of allergic disease, increasing days of use for these indications did not increase the risk of allergic disease. We conclude that paracetamol use in early life is not an independent risk factor for childhood asthma.

As the vast majority of the children in this cohort were exposed to at least one dose of paracetamol, we were unable to assess if any versus no exposure to paracetamol was associated with an increased risk of childhood asthma; instead we examined the effect of increasing frequency of exposure to paracetamol. However, as the primary biological hypothesis presented to explain why paracetamol may increase the risk of asthma implies a dose-response relation, ${ }^{269}$ our finding of no dose-response relation is important evidence against a causal association.

Although we have shown that the association between paracetamol in early life and increased risk of childhood asthma is inflated by confounding by indication, we cannot completely rule out the possibility of a weak association. For the outcome of asthma, our data are consistent (95\% confidence interval) with an adjusted odds ratio between 0.76 and 1.26 for a substantial increase in paracetamol exposure for nonrespiratory indications (exposure shifted from 4 days (25th centile) to 11 days ( 75 th centile), based on the adjusted odds ratio in table 5). For total paracetamol

\begin{tabular}{|c|c|c|c|c|c|c|}
\hline & \multicolumn{2}{|c|}{ Unadjusted } & \multicolumn{2}{|c|}{$\begin{array}{l}\text { Model 2-adjusted } \\
\text { for standard confounders* }\end{array}$} & \multicolumn{2}{|c|}{$\begin{array}{l}\text { Model 3-adjusted } \\
\text { for frequency of infections }\end{array}$} \\
\hline & Odds ratio $(95 \% \mathrm{Cl})$ & $P$ value & Odds ratio $(95 \% \mathrm{Cl})$ & $P$ value & Odds ratio $(95 \% \mathrm{Cl})$ & $P$ value \\
\hline \multicolumn{7}{|c|}{ Early life (up to 2 years) outcomes } \\
\hline Infantile wheeze & $1.45(1.23$ to 1.71$)$ & $<0.01$ & $1.44(1.21$ to 1.71$)$ & $<0.01$ & 1.44 (1.17 to 1.77$)$ & $<0.01$ \\
\hline Infantile eczema & $1.13(0.99$ to 1.30$)$ & 0.08 & $1.16(1.01$ to 1.33$)$ & 0.04 & $1.13(0.97$ to 1.31$)$ & 0.11 \\
\hline Positive skin prick testł & $0.97(0.82$ to 1.14$)$ & 0.68 & $0.96(0.81$ to 1.13$)$ & 0.62 & $0.98(0.82$ to 1.18$)$ & 0.86 \\
\hline \multicolumn{7}{|c|}{ Childhood (5-7 years) outcomes } \\
\hline Asthma & 1.18 (1.00 to 1.39$)$ & 0.05 & $1.16(0.98$ to 1.38$)$ & 0.09 & 1.08 (0.91 to 1.29$)$ & 0.39 \\
\hline Incident asthma§ & $0.94(0.75$ to 1.18$)$ & 0.60 & $0.96(0.76$ to 1.22$)$ & 0.73 & $0.97(0.76$ to 1.25$)$ & 0.83 \\
\hline Allergic rhinitis & 1.21 (1.01 to 1.46$)$ & 0.04 & $1.19(0.99$ to 1.44$)$ & 0.07 & 1.17 (0.96 to 1.43$)$ & 0.12 \\
\hline Eczema & $1.05(0.90$ to 1.22$)$ & 0.52 & $1.09(0.93$ to 1.27$)$ & 0.29 & $1.10(0.93$ to 1.29$)$ & 0.26 \\
\hline
\end{tabular}

Associations expressed as effect per doubling of number of days of intake (regression on $\log _{2}$ (days paracetamol+1)).

*Infant's sex, parental history of asthma, and presence of older siblings at time of birth.

$\dagger$ As per model 2, plus frequency of infections (upper and lower respiratory tract infections, otitis media, and gastrointestinal infections) during first

2 years of life (frequency of each form of infection classified as $0,1-2$, or $\geq 3$ ).

$\ddagger \geq 3 \mathrm{~mm}$ to at least one of six allergens at 2 year test.

$\S$ Excludes children who had lower respiratory symptoms within first 2 years of life. 
Table 5 Associations between paracetamol intake for non-respiratory causes during early life and risk of allergic disease later in childhood

\begin{tabular}{|c|c|c|c|c|c|c|}
\hline & \multicolumn{2}{|c|}{ Unadjusted } & \multicolumn{2}{|c|}{$\begin{array}{l}\text { Model 2-adjusted } \\
\text { for standard confounders* }\end{array}$} & \multicolumn{2}{|c|}{$\begin{array}{c}\text { Model 3-adjusted } \\
\text { for frequency of infections } \dagger\end{array}$} \\
\hline & Odds ratio $(95 \% \mathrm{Cl})$ & P value & Odds ratio $(95 \% \mathrm{Cl})$ & $P$ value & Odds ratio $(95 \% \mathrm{Cl})$ & $P$ value \\
\hline \multicolumn{7}{|c|}{ Early life (up to 2 years) outcomes } \\
\hline Infantile wheeze & $0.92(0.80$ to 1.07$)$ & 0.28 & $0.92(0.79$ to 1.07$)$ & 0.29 & 1.07 (0.88 to 1.29$)$ & 0.51 \\
\hline Infantile eczema & 1.01 (0.88 to 1.16$)$ & 0.89 & 1.03 (0.90 to 1.19$)$ & 0.67 & $1.04(0.90$ to 1.21$)$ & 0.58 \\
\hline Positive skin prick testł & $0.95(0.80$ to 1.13$)$ & 0.58 & $0.95(0.80$ to 1.14$)$ & 0.60 & 0.99 (0.82 to 1.19$)$ & 0.93 \\
\hline \multicolumn{7}{|c|}{ Childhood (5 to 7 years) outcomes } \\
\hline Asthma & $0.95(0.81$ to 1.12$)$ & 0.58 & 0.95 (0.80 to 1.12$)$ & 0.55 & $0.98(0.83$ to 1.17$)$ & 0.85 \\
\hline Incident asthma§ & $0.94(0.73$ to 1.21$)$ & 0.63 & 0.96 (0.74 to 1.24$)$ & 0.74 & 0.97 (0.74 to 1.28$)$ & 0.85 \\
\hline Allergic rhinitis & 1.10 (0.92 to 1.32$)$ & 0.28 & 1.09 (0.91 to 1.31$)$ & 0.36 & 1.13 (0.93 to 1.37$)$ & 0.23 \\
\hline Eczema & 0.98 (0.84 to 1.15$)$ & 0.81 & 1.00 (0.86 to 1.18$)$ & 0.97 & $1.03(0.87$ to 1.21$)$ & 0.75 \\
\hline \multicolumn{7}{|c|}{$\begin{array}{l}\text { Associations expressed as effect per doubling of number of days of intake (regression on } \log _{2} \text { (days paracetamol+1)). } \\
\text { *Infant's sex, parental history of asthma, and presence of older siblings at time of birth. } \\
\dagger \text { As per model } 2 \text {, plus frequency of infections (upper and lower respiratory tract infections, otitis media, and gastrointestinal infections) during first } \\
2 \text { years of life (frequency of each form of infection classified as } 0,1-2 \text {, or } \geq 3 \text { ). } \\
\ddagger \geq 3 \mathrm{~mm} \text { to at least one of six allergens at } 2 \text { year test. } \\
\text { §Excludes children who had lower respiratory symptoms within first } 2 \text { years of life. }\end{array}$} \\
\hline
\end{tabular}

use (regardless of indication), when expressed in terms of the interquartile range, the $95 \%$ confidence interval for the adjusted odds ratio for the same outcome was 0.87 to 1.44 .

\section{Strengths and limitations of study}

The data from this study have several important strengths in assessing the relation between exposure to paracetamol in early life and risk of childhood allergic conditions. The prospective design, with frequent assessment of exposures and early signs of allergic disease, eliminated the potential for recall bias that could occur in retrospective designs. Recording of the indication for use made it possible to infer the presence of confounding by indication in these crude associations. The rate of follow-up in this study was good $(80 \%$ of the cohort), particularly given the seven year study period.

The sampling frame for the Melbourne Atopy Cohort Study is both a strength and limitation. As only children with a family history of allergic disease were recruited, these results should be extrapolated to the general population with care. The benefits of studying infants at high risk are that the outcomes are more common, which increases the relative power of the study, and that infants at high risk are of particular interest as a potential target group for interventions to prevent the development of allergic diseases.

The study has several limitations in assessing the associations between paracetamol intake and risk of allergic disease. The design is observational in nature, so untangling the effects of use of paracetamol and respiratory tract infections is difficult, as the presence of these factors is highly positively correlated. However, the adjusted associations indicate that a history of respiratory tract symptoms, rather than exposure to paracetamol, is more likely to be the true risk factor for allergic disease. We have also examined whether use of paracetamol for respiratory illness increases the risk of a child developing asthma compared with those who were not treated with paracetamol; we found no evidence to support this (although the power to detect such effects was limited in this study). Although we have not been able to have a physician's assessment of asthma in this cohort at age 6 or 7 , we have shown excellent agreement between the ISAAC definition of asthma that is widely used in epidemiological research and that used in this study $(\kappa=0.80,95 \%$ confidence interval 0.70 to 0.91 , unpublished data). The measures of asthma and rhinitis rely on parental report, but these should be reasonably specific, as only symptoms confirmed by a doctor were included. Nevertheless, some mild cases of asthma may have been missed. Also, we were not able to routinely do skin prick tests at the age of 6 or 7 years on the children in this study, so we cannot assess if paracetamol in early life influences risk of atopy (including atopic asthma) later in childhood. Finally, this study assessed only

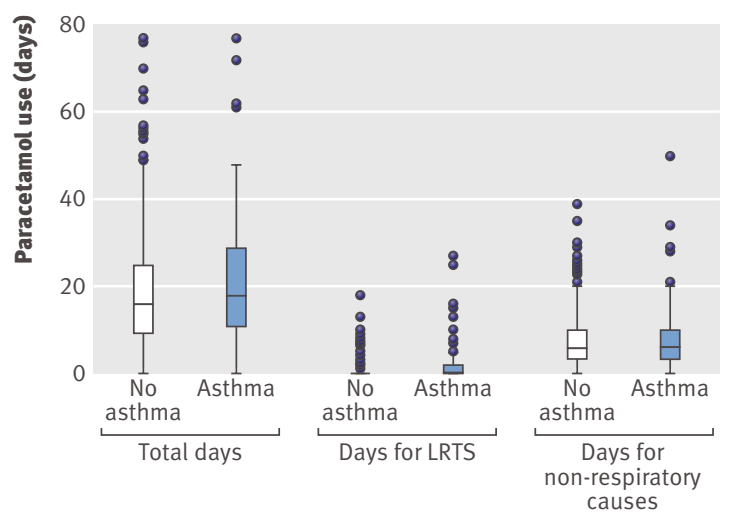

Fig 2 | Days of paracetamol use (by indication) between children with and without asthma in childhood. LRTS=lower respiratory tract symptoms. Box plots show median (centre line) and interquartile range (bottom to top of box) for paracetamol use within first two years of life, for each indication of use, grouped according to whether child did or did not have childhood asthma. Whiskers represent 1.5 times the interquartile range, with outliers beyond this shown as circles 


\section{WHAT IS ALREADY KNOWN ON THIS TOPIC}

Use of paracetamol in early life has been implicated as a cause of asthma by cross sectional studies

No study has yet determined if the association between paracetamol use and increase risk of asthma is due to paracetamol or to the underlying condition that paracetamol is treating

\section{WHAT THIS STUDY ADDS}

No evidence was found of an independent association between paracetamol use and increased risk of childhood asthma or an association with paracetamol use for nonrespiratory tract infections

Use of paracetamol in early life is unlikely to increase the risk of asthma exposure to paracetamol up to 2 years of age. Other groups have implicated exposure to paracetamol during pregnancy or in later childhood as a risk factor for asthma, ${ }^{7242728}$ but we cannot comment on the effects of exposure at these times.

\section{Conclusions and policy implications}

Several authors have called for a randomised trial to determine if exposure to paracetamol in early life increases the risk of allergic disease. ${ }^{2629}$ The logistical problems with such a study would be substantial, as children would need to be followed until at least 7 years of age for a reliable assessment of the outcome of asthma. Use of a placebo control would be ethically fraught, and widespread non-compliance and contamination of the placebo arm would potentially occur. Use of ibuprofen as a control may be possible, but any observed effect could be due to a beneficial effect of ibuprofen rather than paracetamol increasing the risk of allergic disease. The lack of association between use of paracetamol for non-respiratory tract infections and all forms of allergic disease outcomes in this study makes it unlikely that paracetamol is a true cause of allergic disease in otherwise well children.

The apparent association between frequent consumption of paracetamol in early life and increased risk of asthma reported in other studies can be explained as confounding by indication (treatment of respiratory infections with paracetamol). This study does not provide any evidence to suggest that paracetamol is a cause of allergic disease.

We thank John Thorburn for assistance in recruitment of patients and administrative assistance and the Mercy Hospital Department of Obstetrics for recruitment of participants. We are grateful to the late Richard Sporik, who originally suggested to us that the Melbourne Atopy Cohort Study (MACS) database would be a useful tool to use to approach this question. We thank Anne Balloch for assistance with data management and all of the MACS children and parents for their participation and ongoing support for this study.

Contributors: DJH and CSH acquired funding and supervised the study. DJH, CSH, and CA acquired the data. AJL led the analysis and interpretation of data, with support from JBC, SCD, CFR, and CMB. AJL wrote the initial draft of the manuscript, which was critically revised for important intellectual content by all authors. AIL and SCD had full access to the data (including statistical reports and tables) in the study. ALL is the guarantor.

Funding: Dairy Australia, CRC for Asthma, and VicHealth supported AJL during his PhD, when the work presented in the manuscript was first developed. AIL, SCD, and KJA are supported by the National Health and Medical Research Council. Nestec, a subsidiary of Nestlé Australia, provided staff funding for the first six years of the study. The funding bodies had no role in the design, analysis, conduct, or reporting of the study. The opinions, results and conclusions reported in this paper are those of the authors and are independent from the funding sources. Competing interests: All authors have completed the Unified Competing Interest form at www.icmje.org/coi_disclosure.pdf (available on request from the corresponding author) and declare that (1) DJH has received support from Nestec (a subsidiary of Nestlé Australia) for the submitted work; (2) within the previous 3 years, SCD has received a grant from GlaxoSmithKline for unrelated work, MJA received funding from Reckitt Benckiser for an unrelated research project, CFR is on the GlaxoSmithKline Pediatric Asthma Scientific Board, and MJA is on the GlaxoSmithKline Scientific Advisory Committee for the Australian Asthma Study, and these companies might have an interest in the submitted work; (3) all authors their spouses, partners, or children have no other financial relationships that may be relevant to the submitted work; and (4) all authors have no non-financial interests that may be relevant to the submitted work.

Ethical approval: The Mercy Hospital research ethics committee, Melbourne, Australia approved the study. Data sharing: No additional data available.

1 Kogan MD, Pappas G, Yu SM, Kotelchuck M. Over-the-counter medication use among US preschool-age children. JAMA 1994;272:1025-30.

2 Eneli I, Sadri K, Camargo C Jr, Barr RG. Acetaminophen and the risk of asthma: the epidemiologic and pathophysiologic evidence. Chest 2005; 127:604-12.

3 McKeever TM, Lewis SA, Smit HA, Burney P, Britton JR, Cassano PA The association of acetaminophen, aspirin, and ibuprofen with respiratory disease and lung function. Am J Respir Crit Care Med 2005;171:966-71.

4 Barr RG, Wentowski CC, Curhan GC, Somers SC, Stampfer MJ, Schwartz J, et al. Prospective study of acetaminophen use and newly diagnosed asthma among women. Am J Respir Crit Care Med 2004;169:836-41.

5 Lesko SM, Louik C, Vezina RM, Mitchell AA. Asthma morbidity after the short-term use of ibuprofen in children. Pediatrics 2002;109:E20.

6 Lesko SM, Mitchell AA. The safety of acetaminophen and ibuprofen among children younger than two years old. Pediatrics 1999;104:e39.

7 Beasley R, Clayton T, Crane J, von Mutius E, Lai CK, Montefort S, et al. Association between paracetamol use in infancy and childhood, and risk of asthma, rhinoconjunctivitis, and eczema in children aged 6-7 years: analysis from phase three of the ISAAC programme. Lancet 2008:372:1039-48.

8 Micheli L, Cerretani D, Fiaschi Al, Giorgi G, Romeo MR, Runci FM. Effect of acetaminophen on glutathione levels in rat testis and lung. Environ Health Perspect 1994;102(suppl 9):63-4.

9 Dimova S, Hoet PH, Dinsdale D, Nemery B. Acetaminophen decreases intracellular glutathione levels and modulates cytokine production in human alveolar macrophages and type II pneumocytes in vitro. Int J Biochem Cell Biol 2005;37:1727-37.

10 Braman SS. The global burden of asthma. Chest 2006;130:4-12S.

11 Merkus PJ, ten Have-Opbroek AA, Quanjer PH. Human lung growth: a review. Pediatr Pulmonol 1996;21:383-97.

12 Oddy WH, de Klerk NH, Sly PD, Holt PG. The effects of respiratory infections, atopy, and breastfeeding on childhood asthma. Eur Respir / 2002;19:899-905.

13 Jackson DJ, Gangnon RE, Evans MD, Roberg KA, Anderson EL, Pappas TE, et al. Wheezing rhinovirus illnesses in early life predict asthma development in high-risk children. Am J Respir Crit Care Med 2008;178:667-72

14 Celedon JC, Fuhlbrigge A, Rifas-Shiman S, Weiss ST, Finkelstein JA. Antibiotic use in the first year of life and asthma in early childhood. Clin Exp Allergy 2004:34:1011-6.

15 Stein RT, Sherrill D, Morgan WJ, Holberg CJ, Halonen M, Taussig LM, et al. Respiratory syncytial virus in early life and risk of wheeze and allergy by age 13 years. Lancet 1999;354:541-5.

16 Kusel MM, de Klerk NH, Kebadze T, Vohma V, Holt PG, Johnston SL, et al. Early-life respiratory viral infections, atopic sensitization, and risk of subsequent development of persistent asthma. J Allergy Clin Immunol 2007;119:1105-10.

17 Lowe A, Abramson M, Dharmage S, Allen K. Paracetamol as a risk factor for allergic disorders. Lancet 2009;373:120; author reply 120-1.

18 Rockenbauer M, Olsen J, Czeizel AE, Pedersen L, Sorensen HT. Recall bias in a case-control surveillance system on the use of medicine during pregnancy. Epidemiology 2001;12:461-6.

19 Hill AB. The environment and disease: association or causation? Proc $R$ Soc Med 1965;58:295-300. 
20 Lowe AJ, Carlin JB, Bennett CM, Abramson MJ, Hosking CS, Hill DJ, et al. Atopic disease and breastfeeding-cause or consequence? J Allergy Clin Immunol 2006;117:682-7.

21 Aas K, Belin L. Standardization of diagnostic work in allergy. Int Arch Allergy Appl Immunol 1973;45:57-60.

22 Lowe AJ, Hosking CS, Bennett CM, Carlin JB, Abramson MJ, Hill DJ, et al. Skin prick test can identify eczematous infants at risk of asthma and allergic rhinitis. Clin Exp Allergy 2007;37:1624-31.

23 Lowe AJ, Abramson MJ, Hosking CS, Carlin JB, Bennett CM, Dharmage SC, et al. The temporal sequence of allergic sensitization and onset of infantile eczema. Clin Exp Allergy 2007;37:536-42.

24 Shaheen SO, Newson RB, Sherriff A, Henderson AJ, Heron JE, Burney PGJ, et al. Paracetamol use in pregnancy and wheezing in early childhood. Thorax 2002;57:958-63.

25 Cohet C, Cheng S, MacDonald C, Baker M, Foliaki S, Huntington N, et al. Infections, medication use, and the prevalence of symptoms of asthma, rhinitis, and eczema in childhood. J Epidemiol Community Health 2004;58:852-7.

26 Farquhar H, Crane J, Mitchell EA, Eyers S, Beasley R. The acetaminophen and asthma hypothesis 10 years on: a case to answer. J Allergy Clin Immunol 2009;124:649-51.

27 Perzanowski M, Miller R, Tang D, Ali D, Garfinkel R, Chew G, et al. Prenatal acetaminophen exposure and risk of wheeze at age 5 years in an urban low-income cohort. Thorax 2010;65:118-23.

28 Rebordosa C, Kogevinas M, Sorensen HT, Olsen J. Pre-natal exposure to paracetamol and risk of wheezing and asthma in children: a birth cohort study. Int J Epidemiol 2008;37:583-90.

29 Barr RG. Does paracetamol cause asthma in children? Time to remove the guesswork. Lancet 2008;372:1011-2.

Accepted: 16 July 2010 